\title{
Areca Nut Chewing and the Risk of Re-hospitalization and Mortality Among Patients With Acute Coronary Syndrome in Pakistan
}

\author{
Muhammad Tariq Karim', Sumera Inam², Tariq Ashraf ${ }^{3}$, Nadia Shah ${ }^{2}$, Syed Omair Adil ${ }^{4}$, Kashif Shafique ${ }^{2,5}$ \\ ${ }^{1}$ Research Evaluation Unit, College of Physicians and Surgeons Pakistan, Karachi, Pakistan; ${ }^{2}$ School of Public Health, Dow University of Health \\ Sciences, Karachi, Pakistan; ${ }^{3}$ National Institute of Cardiovascular Diseases, Karachi, Pakistan; ${ }^{4}$ Department of Research, Dow University of Health \\ Sciences, Karachi, Pakistan; ${ }^{5}$ Institute of Health and Wellbeing, Public Health, University of Glasgow, Glasgow, UK
}

Objectives: Areca nut is widely consumed in many parts of the world, especially in South and Southeast Asia, where cardiovascular disease (CVD) is also a huge burden. Among the forms of CVD, acute coronary syndrome (ACS) is a major cause of mortality and morbidity. Research has shown areca nut chewing to be associated with diabetes, hypertension, oropharyngeal and esophageal cancers, and CVD, but little is known about mortality and re-hospitalization secondary to ACS among areca nut users and non-users.

Methods: A prospective cohort was studied to quantify the effect of areca nut chewing on patients with newly diagnosed ACS by categorizing the study population into exposed and non-exposed groups according to baseline chewing status. Cox proportional hazards models were used to examine the associations of areca nut chewing with the risk of re-hospitalization and 30-day mortality secondary to ACS.

Results: Of the 384 ACS patients, $49.5 \%(n=190)$ were areca users. During 1-month of follow-up, 20.3\% $(n=78)$ deaths and $25.1 \%$ $(\mathrm{n}=96)$ re-hospitalizations occurred. A higher risk of re-hospitalization was found (adjusted hazard ratio [aHR], 2.05; 95\% confidence interval $[\mathrm{Cl}], 1.29$ to $3.27 ; p=0.002$ ) in areca users than in non-users. Moreover, patients with severe disease were at a significantly higher risk of 30-day mortality (aHR, $2.77 ; 95 \% \mathrm{Cl}, 1.67$ to $4.59 ; p<0.001$ ) and re-hospitalization (aHR, $2.72 ; 95 \% \mathrm{Cl}, 1.73$ to 4.26 ; $p<0.001)$.

Conclusions: The 30-day re-hospitalization rate among ACS patients was found to be significantly higher in areca users and individuals with severe disease. These findings suggest that screening for a history of areca nut chewing may help to identify patients at a high risk for re-hospitalization due to secondary events.

Key words: Areca nut, Acute coronary syndrome, Mortality, Re-hospitalization, Pakistan

Received: November 17, 2017 Accepted: January 12, 2018

Corresponding author: Kashif Shafique, PhD

School of Public Health, Dow University of Health Sciences, Suparco

Road, KDA Scheme-33, Karachi 74200, Pakistan

E-mail: k.shafique@duhs.edu.pk

This is an Open Access article distributed under the terms of the Creative Commons Attribution Non-Commercial License (http://creativecommons.org/licenses/by$\mathrm{nc} / 4.0 /$ ) which permits unrestricted non-commercial use, distribution, and reproduction in any medium, provided the original work is properly cited.

\section{INTRODUCTION}

Approximately 600 million individuals throughout the world chew areca nut, making it the fourth leading form of substance abuse worldwide, and more than a quarter of areca nut users live in South Asia [1,2]. Areca nut chewing is emerging as a public health challenge in many Western countries due to the immigration of youth from Asia and Africa to these coun- 
tries. Areca nuts are the main component of the vast majority of commonly consumed chewing products, including betel quid (paan), gutka, and supari. Areca nut is consumed in several forms, including green/unripe, ripe, raw, boiled/roasted, or fermented, in high-consuming countries such as India (where $46.4 \%$ of males and $20 \%$ of females consume gutka), Pakistan (with areca nut consumption rates of $50.3 \%$ for males and $28.5 \%$ for females) [3], Nepal, Bangladesh, Sri Lanka, Thailand, Malaysia, Indonesia, China, Cambodia, and Papua New Guinea. Additional sweeteners and flavors such as cloves, amber, coconut, mace, sugar crystals, nutmeg, camphor; tobacco, and lime are added as flavor enhancers [2].

Several studies have shown that areca nut chewing is linked with cancer of the oral cavity, esophagus, and liver, as well as cirrhosis of the liver [4-10]. Furthermore, some evidence also suggests that areca nut chewing is linked with obesity, type 2 diabetes mellitus (DM), hypertension (HTN), dyslipidemia, metabolic syndrome, and chronic kidney disease [11-15], which are also well-known risk factors of cardiovascular disease (CVD) $[16,17]$. CVD is still the leading cause of mortality globally, and the South Asian population is expected to significantly contribute to global CVD morbidity and mortality in decades to come.

Evidence from prospective studies suggests that areca nut chewing significantly amplifies the risk of all-cause and cardiovascular mortality $[18,19]$. Betel quid causes instant effects of vasoconstriction, an elevated pulse rate, and raised blood pressure [20]. Since it contains arsenic and manganese, it may increase the risk of HTN in chewers. Further, it also stimulates the sympathetic nervous system, resulting in the secretion of adrenal medullary catecholamine, which is linked to elevated homocysteine levels, another risk factor for heart disease. Moreover, periodontal disease, a known risk factor for CVD, is also a consequence of consuming betel quid [21]. A pooled analysis of 12 studies reported increased risk of developing CVD's (relative risk [RR], 1.20, $p<0.05$ ) and of all-cause mortality $(\mathrm{RR}, 1.21, p<0.05)$ among areca nut chewers compared with non-chewers [22].

Among the forms of CVD, acute coronary syndrome (ACS) accounts for approximately 3.5 million hospital admissions worldwide [23]. Considerable disparities exist in the incidence and mortality of ACS from country to country. These disparities are also partly explained by differences in lifestyle habits and the prevalence of various cardiovascular risk factors [24].

Some evidence suggests that long-term areca nut chewing increases the risk of ACS by 3-fold (odds ratio [OR], 3.5; 95\% confidence interval [Cl], 2.0 to 6.2) [25]. However, there is little published evidence regarding the relationship of long-term areca nut chewing with the prognosis of patients who develop ACS. Given that 15 to $30 \%$ of patients with ACS either are rehospitalized or die within 30 days of the acute event, it is important to understand the effects of areca nut chewing on the prognosis of these patients. Therefore, the purpose of the study was to determine the short-term (30-day) risk of re-hospitalization and mortality among ACS patients according to baseline areca nut chewing.

\section{METHODS}

\section{Study Setting}

This study was a hospital-based prospective cohort study conducted in 2014-2015. The study was conducted at the Department of Cardiology, Civil Hospital Karachi and the National Institute of Cardiovascular Diseases. Both of these are tertiary care hospitals, serving more than $60 \%$ of CVD patients in Karachi, the largest city of Pakistan, at low cost.

\section{Cohort Selection}

ACS represents "a set of clinical sign and symptoms similar to acute myocardial ischemia, covering clinical conditions from unstable angina to none-ST-segment elevation myocardial infarction (NSTEMI) to ST-segment elevation myocardial infarction (STEMI)" [26].

Patients were diagnosed with ACS by a consultant cardiologist at the time of presentation with any of the following conditions:

STEMI: "A history of typical chest pain for more than $20 \mathrm{~min}$ utes with ST elevation at the J point of $\geq 2 \mathrm{~mm}(0.2 \mathrm{mV})$ in at least 2 contiguous leads in males $\geq 1.5 \mathrm{~mm}(0.15 \mathrm{mV})$ in females in leads V2-V3, or $\geq 1 \mathrm{~mm}(0.1 \mathrm{mV})$ in other contiguous chest or the limb leads."

NSTEMI: "A history of typical chest pain for $>20$ minutes with electrocardiogram (ECG) changes such as ST depression and raised creatine kinase-MB (CKMB) enzymes and troponin levels."

Unstable angina: The presence of 1 or more of the following presentations without elevated CKMB enzymes or troponin was labeled as rest angina (usually lasting $>20$ minutes), new-onset angina ( $<2$ months previously), or an increased pattern of occurrence (increasing in duration, intensity, and/ or frequency). 
Only newly admitted patients 30-70 years of age with a diagnosis of ACS at the time of admission were included in the study. Subjects with congenital heart disease, any previous or family history of ACS, or valvular or rheumatic heart disease were excluded from this study.

\section{Data Collection Tool}

A standardized questionnaire was used by a team of welltrained researchers to interview patients, gathering information about their demographic characteristics, lifestyle, health behaviors, and history of chewing areca nut. All information was collected by face-to-face interviews with patients within the first 48 hours of hospital admission.

The socio-demographic measures included age (30-40, 40$50,50-60$, and $>60$ years), sex (male or female), monthly income (used to define socioeconomic status [SES] as below average or average) and employment status (employed or unemployed). Health behaviors, particularly physical activity, were captured through self-reporting, and patients who reported no activity or less than 150 minutes of activity per week were labeled as physically inactive. Patients were also asked about their smoking status, and based on their responses were classified as "never smokers (those who had never smoked a cigarette), current smokers (those who reported smoking at least 100 cigarettes during their lifetime and reported smoking every day or some days at the time of participation), and ex-smokers (individuals who had quit smoking for at least 6 months)". Physical measures included measurements of weight, height, blood pressure, and body mass index $\left(\mathrm{BMI}, \mathrm{kg} / \mathrm{m}^{2}\right)$. BMl was categorized according to the standard World Health Organization BMI cut-offs that classify "normal weight as $<23.0 \mathrm{~kg} / \mathrm{m}^{2}$, overweight as $23.0-26.9 \mathrm{~kg} / \mathrm{m}^{2}$, and obese as $\geq 27.0 \mathrm{~kg} / \mathrm{m}^{2 \prime}$ [27]. Patients were classified as having DM if they had "a self-reported history of DM, were on anti-diabetic medications, or had abnormal fasting blood glucose levels (blood glucose concentration $\geq 110 \mathrm{mg} / \mathrm{dL}$ )." HTN was defined as "a blood pressure $\geq 140$ (systolic)/90 (diastolic) $\mathrm{mmHg}$, previously diagnosed HTN, the usage of anti-hypertensive medications".

According to the guidelines of the American Heart Association, the current pathway for assessing patients who may have ACS is based on the following 4 main diagnostic tools: "clinical history, ECG results, levels of cardiac markers, and the results of stress testing. On the basis of this initial information, patients are assigned to one of 4 categories: a non-cardiac diag- nosis, chronic stable angina, possible ACS, or definite ACS". Based on the diagnosis made by the cardiologist, we generated a variable for the initial severity of disease. Respondents with 'unstable/mild angina' were classified as having 'non-severe disease', whereas 'possible myocardial infarction/definite' ACS were considered to indicate 'severe initial disease'.

\section{Exposure Definition}

Patients who persistently consumed areca nut on daily basis (on average 2-3 times a day) for more than 5 years were considered to be exposed $[28,29]$, and were coded as 'yes' for this variable, while those who never used or had quit consuming areca for more than a year were considered to be non-exposed and coded as ' $n o$ ' for this variable. Patients categorized as exposed were asked about the form of areca nut they used. Respondents who consumed "unripe or ripe; whole or sliced; raw, roasted, or sun-dried; boiled or soaked in water; or fermented (under mud) areca nut" were considered to consume areca nut 'without additives.' In contrast, "mixtures of areca nut and flavoring ingredients with processed tobacco leaves, slaked lime, catechus, sweeteners, spices, piper betel, and essences" were considered to be forms'with additives or tobacco' [30].

\section{Follow-up}

The follow-up of ACS patients started once they were discharged from the hospital. Patients were followed regularly in the outpatient clinic, and the final outcomes were recorded after 30 days had passed from the time of discharge. The outcomes: 30-day mortality and 30-day re-hospitalization were measured separately. Mortality was defined as death within 30 days due to any cardiac problem from the index admission date, and re-hospitalization was defined as readmission to the hospital due to any cardiac problem within 30 days from the discharge date. Therefore, 2 survival times were defined: the time from entry to death from CVD (within 30 days) and the time from entry to re-hospitalization (within 30 days) due to any cardiac problems.

For patients who did not return in 30 days, a telephone call was made by the researchers to evaluate their vital status and any cardiac re-hospitalization event in the 30 days after discharge. Only the first re-hospitalization within 30 days of discharge was considered a 30-day readmission. However, if a readmitted patient died within this 30 -day period, then in the re-hospitalization multivariate model, that patient's follow-up was truncated at the date of re-hospitalization. 


\section{Sample Size Estimation}

The sample size was calculated using the expected proportions of mortality in the exposed (30\%) [31] and unexposed (15\%) groups with a $95 \%$ confidence level and $80 \%$ power of the test. Accordingly, the minimum sample size for this study was 268, which was upsized to reduce estimation bias from loss to follow-up. The final estimated sample size was 384 .

\section{Ethical Approval}

The study protocol was approved by the institutional review board (IRB) of Dow University of Health Sciences, Karachi, Pakistan (IRB no. IRB-514/DUHS/-14). Informed consent was obtained from all study participants prior to conducting the study.

\section{Statistical Analysis}

For data analysis, Stata version 11 (StataCorp., College Station, TX, USA) was used. Demographic characteristics, history of substance use, and the prevalence of comorbidities in patients with ACS were recorded. The statistical analysis included the chi-square test, as well as Cox proportional hazards regression with a significance level of 0.05 to examine the associations of areca use and other explanatory variables with 30-day mortality and re-hospitalization, which were the dependent variables used in the current study. Univariate analyses were performed using a Cox proportional hazards regression model to estimate the magnitude of the effect of areca nut chewing on 30-day mortality and re-hospitalization of ACS patients. Multivariable proportional hazards regression models were further applied, and the adjusted hazard ratio (aHR) for areca nut chewing was computed after adjusting for the confounders identified in the univariate analyses $(p=0.25)$ separately for both 30-day mortality and re-hospitalization, including the following covariates: age, sex, BMI, smoking status, initial severity of disease, SES, exercise status, employment status, DM, and HTN.

\section{RESULTS}

A total of 384 patients with ACS were included in this study, among whom $38.2 \%(n=147)$ were diagnosed with severe disease. During 1-month follow-up, death occurred in $20.3 \%$ $(n=78)$ of the patients and re-hospitalization in $25.0 \%(n=96)$. Of the patients, $49.5 \%(n=190)$ were areca nut users, among whom $78.9 \%(n=150)$ were users of areca nut with additives.
A significant association was observed between areca use and 30-day re-hospitalization $(p<0.001)$.

Further, significant associations were found between disease severity and 30 -day mortality $(p<0.001)$ and re-hospitalization $(p<0.001)$. Among the patients with severe initial disease, 39.5\% $(n=58)$ were re-hospitalized and $34.0 \%(n=50)$ died within the 1-month follow-up.

Of the ACS patients, $72.1 \%(n=277)$ were male and $27.9 \%$ $(n=107)$ were female. Males were more likely to use areca nut with tobacco additives than females $(p=0.008)$. Death within 30 days occurred in $22.0 \%(n=61)$ of the male patients and $15.9 \%(n=17)$ of the female patients, and re-hospitalization took place in $25.6 \%(n=71)$ of the male patients and $23.4 \%$ $(n=25)$ of the female patients. However, no statistically significant association was found between sex and 30-day mortality ( $p=0.18$ ) or 30 -day re-hospitalization $(p=0.65)$.

Of the 286 smokers, $29.6 \%(n=114)$ were current smokers and $18.8 \%(n=72)$ were ex-smokers. The 30 -day mortality rate was $32.5 \%(n=37)$ and $13.9 \%(n=10)$ in current smokers and ex-smokers, respectively, and the 30-day re-hospitalization rate was $35.1 \%(n=40)$ and $19.4 \%(n=14)$ in current smokers and ex-smokers, respectively. Respondents with a normal BMI $(n=80)$, overweight $(n=200)$, and obesity $(n=104)$ had 30 day mortality rates of $23.7 \%(n=19), 24.0 \%(n=48)$, and $10.6 \%$ $(n=11)$, respectively, and 30-day re-hospitalization rates of $28.8 \%(n=23), 27.0 \%(n=54)$, and $18.3 \%(n=19)$, respectively. The chi-square test showed significant associations of current smoking with 30 -day mortality $(p<0.01)$ and re-hospitalization $(p=0.01)$. Furthermore, BMI was also significantly ( $p=$ 0.01 ) associated with mortality among the ACS patients.

Among the patients with DM, $12.9 \%(n=17)$ died, whereas $87.1 \%(n=115)$ remained alive over the 30-day follow-up, and $19.7 \%(n=26)$ were re-hospitalized. Similarly, among patients with HTN, 16.4\% $(n=32)$ and $23.6 \%(n=46)$ died and were rehospitalized, respectively. A significant association was observed between DM and 30-day mortality $(p=0.009)$. There were no significant associations of mortality and re-hospitalization with age, SES, employment status, or HTN. Table 1 summarizes the basic characteristics of the study sample.

\section{Univariate Analyses}

In the univariate Cox proportional hazards regression analyses, areca nut users had a higher risk of 30-day re-hospitalization (hazard ratio $[\mathrm{HR}], 2.09 ; 95 \% \mathrm{Cl}, 1.37$ to $3.18 ; p<0.001$ ) and 30 -day mortality $(\mathrm{HR}, 1.43 ; 95 \% \mathrm{Cl}, 0.91$ to $2.24 ; p=0.11)$ 


\section{Journal of}

Table 1. Baseline characteristics by status mortality and re-hospitalization ( $\mathrm{n}=384)$

\begin{tabular}{|c|c|c|c|c|c|c|c|}
\hline \multirow{2}{*}{ Characteristics } & \multirow{2}{*}{ Total } & \multicolumn{3}{|c|}{ Re-hospitalization } & \multicolumn{3}{|c|}{ Mortality } \\
\hline & & Yes & No & $p$-value ${ }^{1}$ & Yes & No & $p$-value ${ }^{1}$ \\
\hline \multicolumn{8}{|l|}{ Areca use } \\
\hline No & $194(50.5)$ & $33(17.0)$ & $161(82.9)$ & \multirow[t]{2}{*}{$<0.001$} & $33(17.0)$ & $161(82.9)$ & \multirow[t]{2}{*}{0.10} \\
\hline Yes & $190(49.5)$ & 63 (33.2) & $127(66.8)$ & & $45(23.7)$ & $145(76.3)$ & \\
\hline \multicolumn{8}{|l|}{ Areca type $(n=190)$} \\
\hline Without additive & $40(21.1)$ & $14(35.0)$ & $26(65.0)$ & \multirow[t]{2}{*}{0.78} & $12(30.0)$ & $28(70.0)$ & \multirow[t]{2}{*}{0.29} \\
\hline Additive & $150(78.9)$ & 49 (32.7) & $101(67.3)$ & & $33(22.0)$ & $117(78.0)$ & \\
\hline \multicolumn{8}{|l|}{ Smoking status } \\
\hline Never smoked & $198(51.5)$ & $42(21.2)$ & $156(78.8)$ & \multirow[t]{3}{*}{0.01} & $31(15.6)$ & $167(84.3)$ & \multirow[t]{3}{*}{$<0.001$} \\
\hline Current smokers & $114(29.6)$ & $40(35.1)$ & $74(64.9)$ & & 37 (32.5) & 77 (67.5) & \\
\hline Ex-smokers & $72(18.8)$ & $14(19.4)$ & $58(80.6)$ & & $10(13.9)$ & $62(86.1)$ & \\
\hline \multicolumn{8}{|l|}{ Disease sverity } \\
\hline No & $237(61.7)$ & $38(16.0)$ & $199(83.9)$ & \multirow[t]{2}{*}{$<0.001$} & $28(11.8)$ & $209(88.2)$ & \multirow[t]{2}{*}{$<0.001$} \\
\hline Yes & $147(38.2)$ & 58 (39.5) & $89(60.5)$ & & $50(34.0)$ & $97(65.9)$ & \\
\hline \multicolumn{8}{|l|}{ Age (y) } \\
\hline $30-40$ & $50(13.0)$ & $12(24.0)$ & $38(76.0)$ & \multirow[t]{4}{*}{0.23} & $9(18.0)$ & $41(82.0)$ & \multirow[t]{4}{*}{0.26} \\
\hline $40-50$ & $116(30.2)$ & $31(26.7)$ & 85 (73.3) & & $30(25.9)$ & $86(74.1)$ & \\
\hline $50-60$ & $121(31.5)$ & $23(19.0)$ & 98 (80.9) & & $19(15.7)$ & $102(84.3)$ & \\
\hline$>60$ & $97(25.3)$ & 30 (30.9) & $67(69.1)$ & & $20(20.6)$ & 77 (79.4) & \\
\hline \multicolumn{8}{|l|}{ Sex } \\
\hline Male & $277(72.1)$ & $71(25.6)$ & $206(74.4)$ & \multirow[t]{2}{*}{0.65} & $61(22.0)$ & $216(77.9)$ & \multirow[t]{2}{*}{0.18} \\
\hline Female & $107(27.9)$ & 25 (23.4) & 82 (76.6) & & $17(15.9)$ & 90 (84.1) & \\
\hline \multicolumn{8}{|l|}{ Body mass index } \\
\hline Normal & $80(20.8)$ & 23 (28.8) & 57 (71.2) & \multirow[t]{3}{*}{0.17} & $19(23.7)$ & $61(76.3)$ & 0.01 \\
\hline Over weight & $200(52.1)$ & $54(27.0)$ & $146(73.0)$ & & $48(24.0)$ & $152(76.0)$ & \\
\hline Obese & $104(27.1)$ & $19(18.3)$ & $85(81.7)$ & & $11(10.6)$ & $93(89.4)$ & \\
\hline Socioeconomic stat & & & & & & & \\
\hline Below average & $117(30.5)$ & 24 (20.5) & 93 (79.5) & 0.18 & $17(14.5)$ & 100 (85.5) & 0.06 \\
\hline Average & $267(69.5)$ & 72 (26.9) & $195(73.0)$ & & 61 (22.8) & $206(77.2)$ & \\
\hline Occupation & & & & & & & \\
\hline Unemployed & $159(41.4)$ & $33(20.8)$ & $126(79.2)$ & 0.11 & $25(15.7)$ & $134(84.3)$ & 0.06 \\
\hline Employed & $225(58.6)$ & $63(28.0)$ & $162(72.0)$ & & $53(23.5)$ & $172(76.4)$ & \\
\hline Physically active & & & & & & & \\
\hline No & 343 (89.3) & 91 (26.5) & 252 (73.5) & 0.04 & $71(20.7)$ & $272(79.3)$ & 0.59 \\
\hline Yes & $41(10.7)$ & $5(12.2)$ & $36(87.8)$ & & $7(17.1)$ & 34 (82.9) & \\
\hline Diabetes mellitus & & & & & & & \\
\hline No & $252(65.6)$ & 70 (27.8) & $182(72.2)$ & 0.08 & $61(24.2)$ & $191(75.8)$ & 0.009 \\
\hline Yes & $132(34.4)$ & $26(19.7)$ & $106(80.3)$ & & $17(12.9)$ & $115(87.1)$ & \\
\hline Hypertension & & & & & & & \\
\hline No & $189(49.2)$ & 50 (26.5) & $139(73.5)$ & 0.52 & $46(24.3)$ & $143(75.7)$ & 0.05 \\
\hline Yes & 195 (50.8) & $46(23.6)$ & 149 (76.4) & & $32(16.4)$ & 163 (83.6) & \\
\hline
\end{tabular}

Values are presented as number (\%).

${ }^{1}$ Chi-square test.

than non-users. Moreover, patients with severe disease had a higher risk of both 30-day re-hospitalization ( $\mathrm{HR}, 2.69 ; 95 \% \mathrm{Cl}$,
1.79 to $4.06 ; p<0.001)$ and 30-day mortality $(\mathrm{HR}, 3.17 ; 95 \% \mathrm{Cl}$, 1.99 to $5.03 ; p<0.001)$. Current smokers also had a higher risk 
of both 30 -day mortality (HR, 2.23; $95 \% \mathrm{Cl}, 1.38$ to 3.59 ; $p<0.001)$ and 30-day re-hospitalization $(\mathrm{HR}, 1.73 ; 95 \% \mathrm{Cl}, 1.12$ to $2.67 ; p=0.01$ ) than non-smokers. Respondents who were obese or had DM had a significantly lower risk of 30-day mortality (Table 2).

Table 2. Areca nut use and risk of 30-day re-hospitalization and mortality among ACS patients: univariate analysis ${ }^{1}$

\begin{tabular}{|c|c|c|c|c|}
\hline \multirow{2}{*}{ Characteristics } & \multicolumn{2}{|c|}{ Re-hospitalization } & \multicolumn{2}{|c|}{ Mortality } \\
\hline & HR (95\% CI) & $p$-value & HR (95\% CI) & $p$-value \\
\hline \multicolumn{5}{|l|}{ Areca use } \\
\hline No & 1.00 (reference) & & 1.00 (reference) & \\
\hline Yes & $2.09(1.37,3.18)$ & $<0.001$ & $1.43(0.91,2.24)$ & 0.11 \\
\hline \multicolumn{5}{|l|}{ Areca type } \\
\hline Without additive & 1.00 (reference) & & 1.00 (reference) & \\
\hline Additive & $0.98(0.54,1.79)$ & 0.97 & $0.74(0.38,1.44)$ & 0.39 \\
\hline \multicolumn{5}{|l|}{ Smoking status } \\
\hline Never smoked & 1.00 (reference) & & 1.00 (reference) & \\
\hline Current smokers & $1.73(1.12,2.67)$ & 0.01 & $2.23(1.38,3.59)$ & $<0.001$ \\
\hline \multicolumn{5}{|l|}{ Disease severity } \\
\hline No & 1.00 (reference) & & 1.00 (reference) & \\
\hline Yes & $2.69(1.79,4.06)$ & $<0.001$ & $3.17(1.99,5.03)$ & $<0.001$ \\
\hline \multicolumn{5}{|l|}{ Age (y) } \\
\hline $30-40$ & 1.00 (reference) & & 1.00 (reference) & \\
\hline $40-50$ & $1.16(0.59,2.27)$ & 0.65 & $1.47(0.70,3.11)$ & 0.30 \\
\hline $50-60$ & $0.80(0.40,1.62)$ & 0.55 & $0.85(0.38,1.86)$ & 0.71 \\
\hline$>60$ & $1.41(0.72,2.75)$ & 0.31 & $1.17(0.53,2.58)$ & 0.69 \\
\hline \multicolumn{5}{|l|}{ Sex } \\
\hline Male & 1.00 (reference) & & 1.00 (reference) & \\
\hline Female & $0.89(0.56,1.41)$ & 0.64 & $0.68(0.40,1.18)$ & 0.17 \\
\hline \multicolumn{5}{|l|}{ Body mass index } \\
\hline Normal & 1.00 (reference) & & 1.00 (reference) & \\
\hline Over weight & $0.93(0.57,1.52)$ & 0.79 & $1.04(0.61,1.77)$ & 0.87 \\
\hline Obese & $0.59(0.32,1.08)$ & 0.09 & $0.42(0.20,0.89)$ & 0.02 \\
\hline \multicolumn{5}{|l|}{ Socioeconomic status } \\
\hline Average & 1.00 (reference) & & 1.00 (reference) & \\
\hline Below average & $0.75(0.47,1.19)$ & 0.234 & $0.61(0.36,1.05)$ & 0.08 \\
\hline \multicolumn{5}{|l|}{ Occupation } \\
\hline Un-employed & 1.00 (reference) & & 1.00 (reference) & \\
\hline Employed & $0.68(0.45,1.04)$ & 0.08 & $0.62(0.39,1.01)$ & 0.06 \\
\hline \multicolumn{5}{|l|}{ Physically active } \\
\hline No & 1.00 (reference) & & 1.00 (reference) & \\
\hline Yes & $0.41(0.16,1.02)$ & 0.057 & $0.76(0.35,1.65)$ & 0.49 \\
\hline \multicolumn{5}{|l|}{ Diabetes mellitus } \\
\hline No & 1.00 (reference) & & 1.00 (reference) & \\
\hline Yes & $0.66(0.42,1.03)$ & 0.07 & $0.49(0.28,0.84)$ & 0.01 \\
\hline \multicolumn{5}{|l|}{ Hypertension } \\
\hline No & 1.00 (reference) & & 1.00 (reference) & \\
\hline Yes & $0.87(0.58,1.30)$ & 0.51 & $0.64(0.41,1.01)$ & 0.06 \\
\hline
\end{tabular}

ACS, acute coronary syndrome; HR, hazard ratios; $\mathrm{Cl}$, confidence interval.

${ }^{1}$ Cut-off $\leq 0.25$ : a univariate cut-off value to shortlist variables for multivariable analyses. 


\section{Multivariate Analyses}

Areca nut chewers had a significantly increased risk (aHR, $2.05 ; 95 \% \mathrm{Cl}, 1.29$ to $3.27 ; p=0.002$ ) of re-hospitalization within 30-days compared with non-chewers after adjusting for disease severity, SES, employment status, physical activity, smoking status, and DM. Patients diagnosed with severe disease had a significantly higher risk of re-hospitalization (aHR, 2.72; $95 \% \mathrm{Cl}, 1.73$ to $4.26 ; p<0.001$ ). Current smokers (aHR, 1.28; $95 \% \mathrm{Cl}, 0.81$ to $2.04 ; p=0.28$ ) had a higher but non-significantly increased risk of re-hospitalization compared with nonsmokers. Respondents who had below-average SES, were unemployed, were physically active, or had DM showed lower but non-significantly reduced risks of 30-day re-hospitalization.
Respondents who chewed areca nut had a slightly increased risk of 30-day mortality (aHR, $1.65 ; 95 \% \mathrm{Cl}, 0.99$ to 2.75 ; $p=0.05$ ) compared with non-chewers after adjusting for sex disease severity, SES, employment status, smoking status, DM, and HTN. However, we also observed a significant higher risk of 30-day mortality (aHR, 2.77; $95 \% \mathrm{Cl}, 1.67$ to $4.59 ; p<0.001$ ) among patients with severe disease. Females (aHR, 1.15; 95\% $\mathrm{Cl}, 0.54$ to $2.42 ; p=0.71$ ) were found to be at a higher but nonsignificant increased risk for 30-day mortality compared with males. Individuals, who had below-average SES, were unemployed, or had DM or HTN had a lower but non-significant reduced risk of 30-day mortality (Table 3).

The overall findings of a significant increase in the risk of rehospitalization and a non-significant increase in the risk of

Table 3. Areca nut use and risk of 30-day mortality and re-hospitalization among ACS patients: multivariate analysis

\begin{tabular}{|c|c|c|c|c|}
\hline \multirow{2}{*}{ Characteristics } & \multicolumn{2}{|c|}{ Re-hospitalization ${ }^{1}$} & \multicolumn{2}{|c|}{ Mortality $^{2}$} \\
\hline & aHR $(95 \% \mathrm{CI})$ & $p$-value & aHR $(95 \% \mathrm{CI})$ & $p$-value \\
\hline \multicolumn{5}{|l|}{ Areca use } \\
\hline No & 1.00 (reference) & & 1.00 (reference) & \\
\hline Yes & $2.05(1.29,3.27)$ & 0.002 & $1.65(0.99,2.75)$ & 0.05 \\
\hline \multicolumn{5}{|l|}{ Smoking status } \\
\hline Never smoked & 1.00 (reference) & & 1.00 (reference) & \\
\hline Current smokers & $1.28(0.81,2.04)$ & 0.28 & $1.61(0.91,2.84)$ & 0.10 \\
\hline \multicolumn{5}{|l|}{ Disease severity } \\
\hline No & 1.00 (reference) & & 1.00 (reference) & \\
\hline Yes & $2.72(1.73,4.26)$ & $<0.001$ & $2.77(1.67,4.59)$ & $<0.001$ \\
\hline \multicolumn{5}{|l|}{ Sex } \\
\hline Male & & & 1.00 (reference) & \\
\hline Female & - & - & $1.15(0.54,2.42)$ & 0.71 \\
\hline \multicolumn{5}{|l|}{ SES } \\
\hline Average & 1.00 (reference) & & 1.00 (reference) & \\
\hline Below average & $0.87(0.52,1.46)$ & 0.62 & $0.75(0.41,1.36)$ & 0.35 \\
\hline \multicolumn{5}{|l|}{ Employment status } \\
\hline Unemployed & 1.00 (reference) & & 1.00 (reference) & \\
\hline Employed & $0.76(0.46,1.25)$ & 0.29 & $0.82(0.45,1.50)$ & 0.52 \\
\hline \multicolumn{5}{|l|}{ Physical activity } \\
\hline No & 1.00 (reference) & & & \\
\hline Yes & $0.51(0.20,1.27)$ & 0.15 & - & - \\
\hline \multicolumn{5}{|l|}{ DM } \\
\hline No & 1.00 (reference) & & 1.00 (reference) & \\
\hline Yes & $0.77(0.46,1.27)$ & 0.31 & $0.55(0.29,1.03)$ & 0.06 \\
\hline \multicolumn{5}{|l|}{ HTN } \\
\hline No & & & 1.00 (reference) & \\
\hline Yes & - & - & $0.73(0.43,1.26)$ & 0.27 \\
\hline
\end{tabular}

ACS, acute coronary syndrome; aHR, adjusted hazard ratios; Cl, confidence interval; SES, socioeconomic status; DM, diabetes mellitus; HTN, hypertension. ${ }^{1}$ Adjusted for severity SES, employment status, physical activity, smoking status and DM.

${ }^{2}$ Adjusted for severity, sex, SES, employment status, smoking status, DM and HTN. 

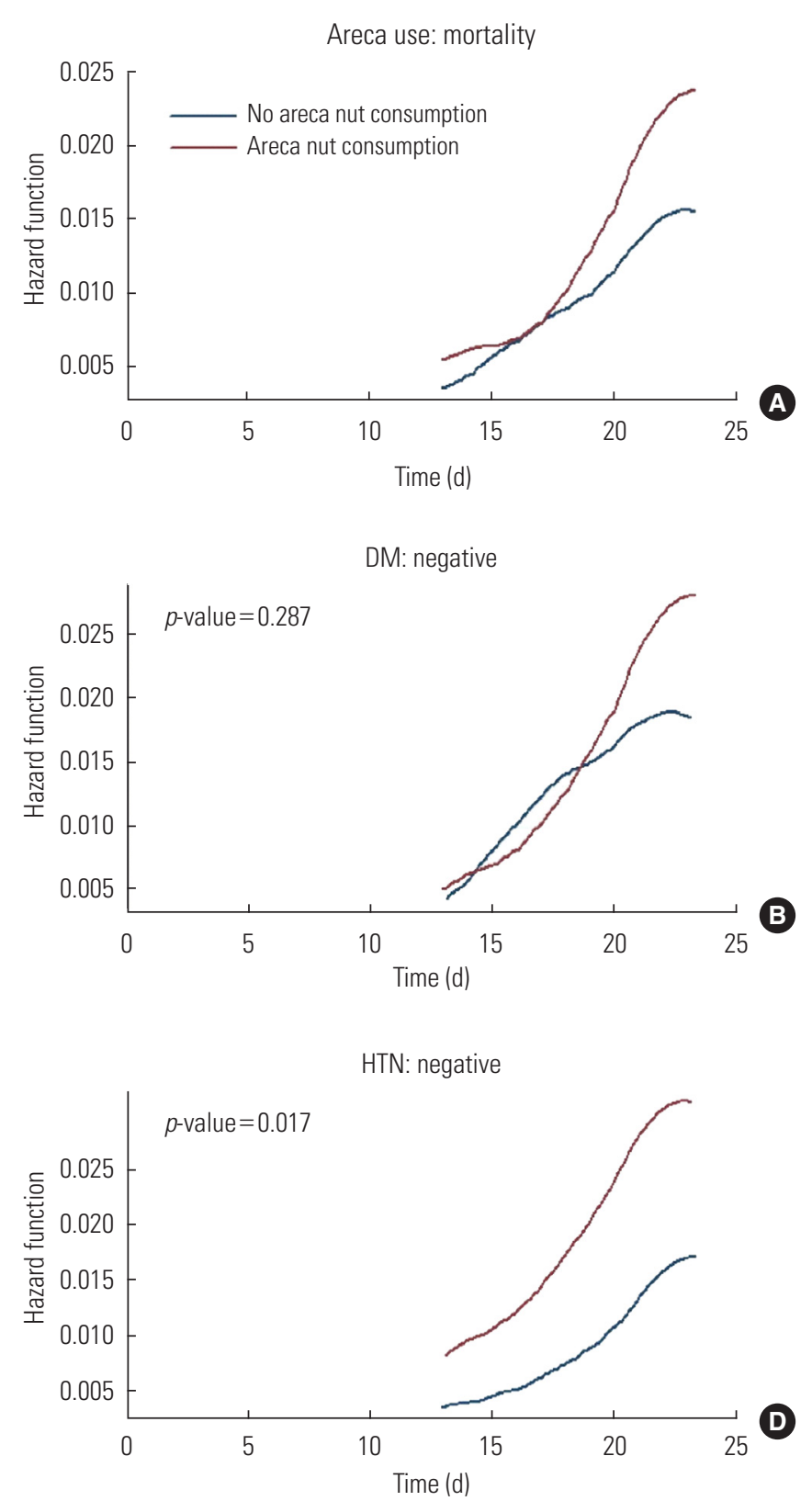

mortality remained consistent when the analyses were stratified based on HTN (Figure 1) and DM (Figure 2).

\section{DISCUSSION}

The findings of this study suggest that ACS patients who are long-term users of areca nut may have a slightly higher risk of 30-day mortality than non-users. This finding was not statistically significant when we controlled for other potential confounding factors such as smoking status, SES, the severity of disease, sex, and history of HT or DM. However, the severity of disease in ACS patients was found to be significantly related to
Figure 1. Thirty-day mortality in acute coronary syndrome patients according to areca nut consumption stratified by DM and HTN. (A) Areca nut use and 30-day mortality risk. (B, C) Areca nut use and mortality stratified by the presence of DM. $(D, E)$ Areca nut use and mortality stratified by the presence of HTN. DM, diabetes mellitus; HTN, hypertension.
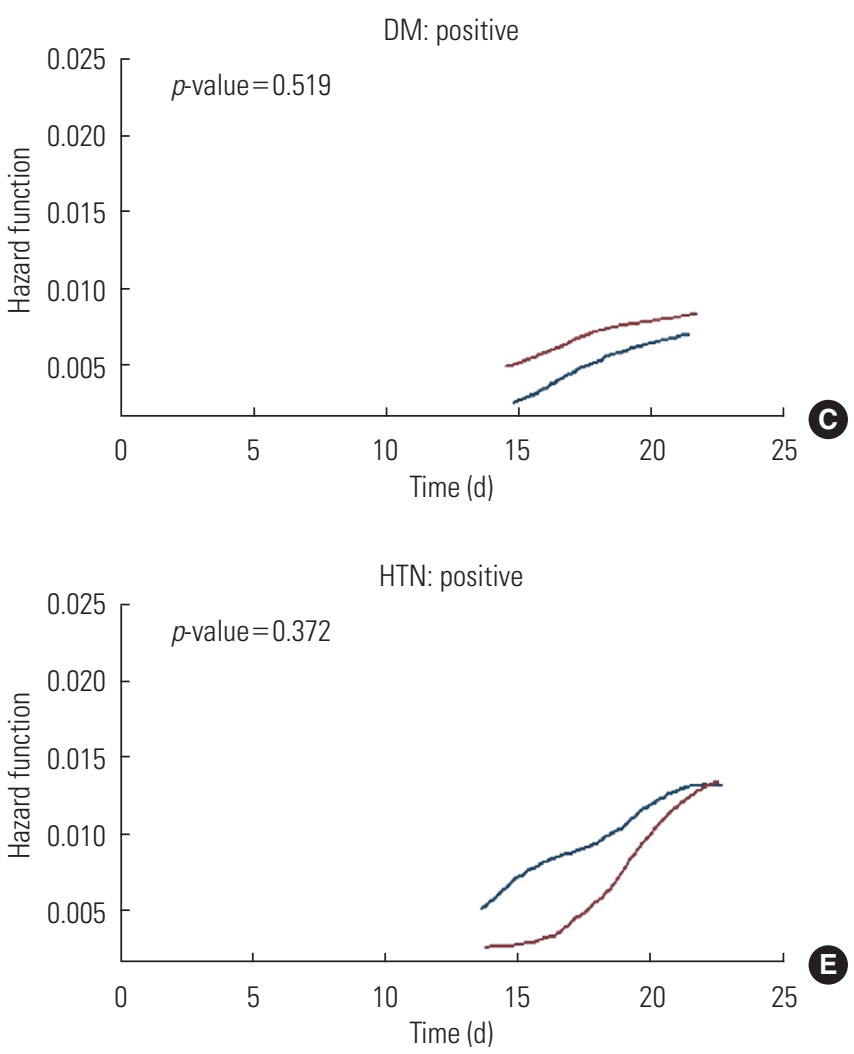

the risk of 30-day re-hospitalization and mortality. Furthermore, we observed a significantly higher risk of 30-day re-hospitalization among ACS patients who were areca nut users than among non-users. The doubled risk of re-hospitalization remained consistent when we accounted for the effects of age, sex, severity of disease, history of HTN, and other covariates. These findings are not directly comparable with any published findings, as to our knowledge no previous evidence has been reported regarding the relationship of areca nut chewing to the prognosis of ACS patients.

Some studies have reported that areca nut chewers had significantly higher risks of cardiovascular and all-cause mortality 

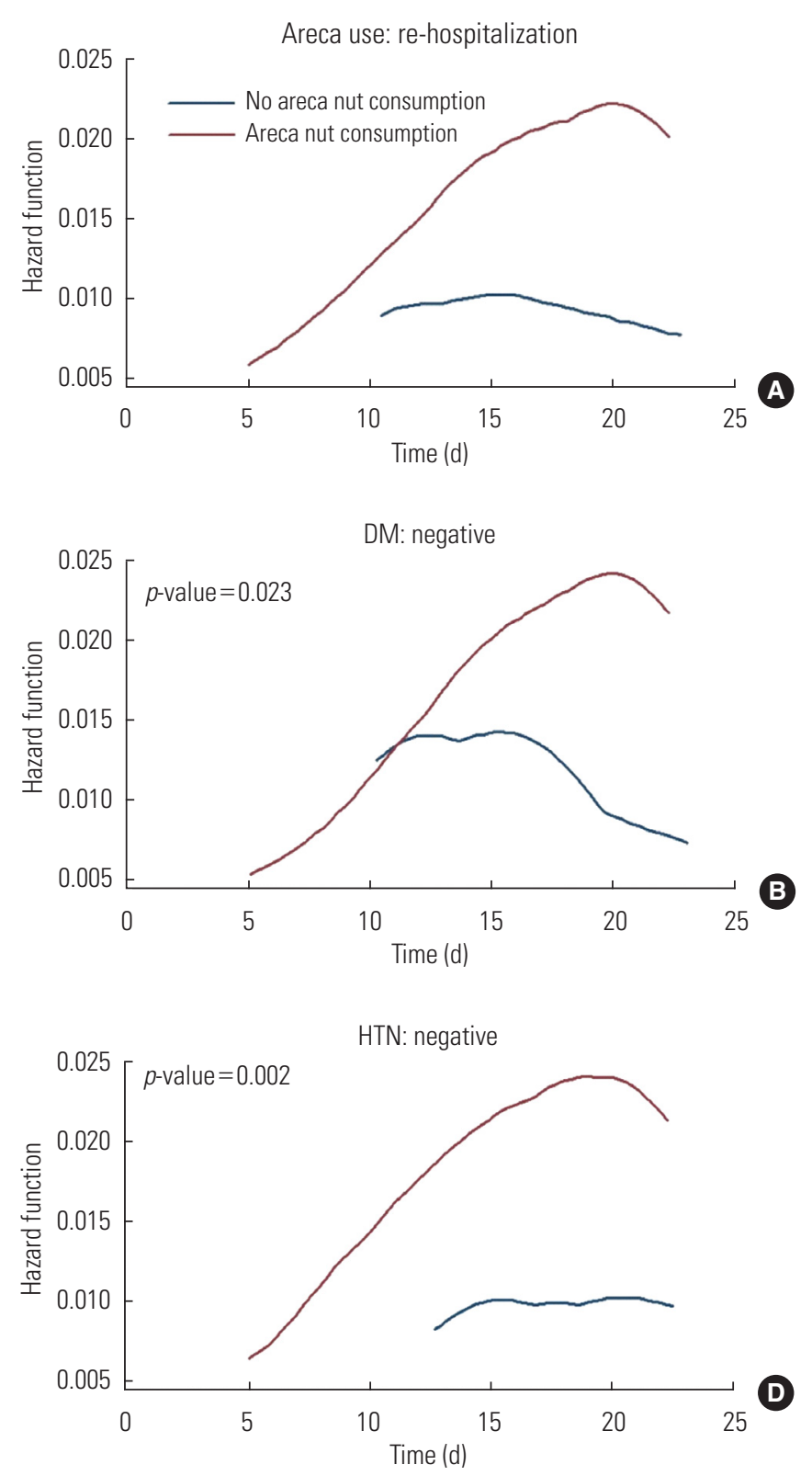

than non-users $[18,19]$. The increase in mortality may be due to a higher risk of developing coronary artery disease [25], atrial fibrillation [32], and other forms of CVD [22] in the first place among areca nut chewers than among non-chewers. Since areca nut chewers are at a higher risk of developing CVD's, they may experience high rates of cardiovascular and all-cause mortality later on compared with non-chewers. Our study also highlights the role of areca nut chewing in the prognosis of ACS patients after the acute event. Our findings suggest a slight increase in mortality and a significant risk of re-hospitalization among chewers compared with non-chewers. Several potential pathways can explain the observed dif-
Figure 2. Re-hospitalization in acute coronary syndrome patients according to areca nut consumption stratified by DM and HTN. (A) Areca nut use and 30-day re-hospitalization risk. $(B, C)$ Areca nut use and 30-day re-hospitalization stratified by the presence of DM. (D, E) Areca nut use and 30-day rehospitalization stratified by the presence of HTN. DM, diabetes mellitus; HTN, hypertension.
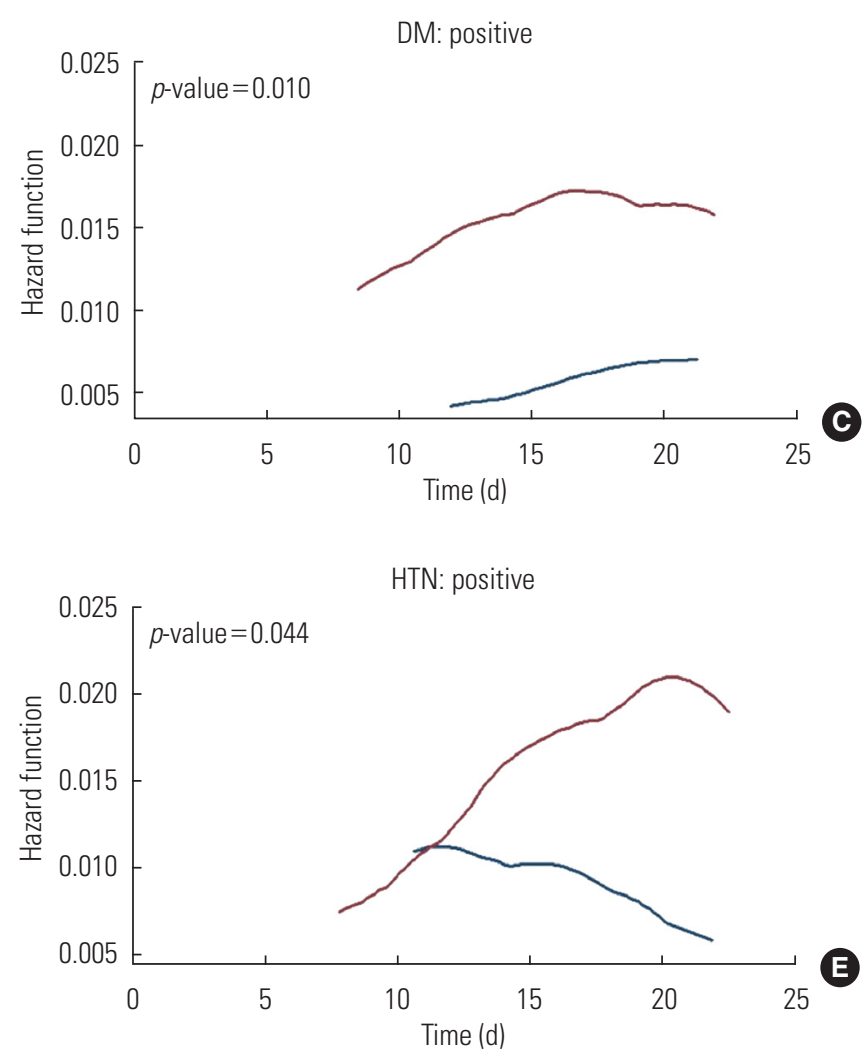

ference in mortality and re-hospitalization between areca nut chewers and non-chewers.

Areca nut chewing is strongly linked with established CVD risk factors, including obesity [33], HTN [21], DM, and metabolic syndrome. Furthermore, recent studies have also reported that areca nut chewing increased systemic inflammation both in young [34] and middle-aged individuals [33]. Elevated inflammation may also explain the observation of subclinical atherosclerosis manifesting as increased carotid intima media thickness among areca nut chewers compared with nonchewers [20]. In essence, the higher prevalence of CVD risk factors coupled with elevated systemic inflammation and un- 
derlying atherosclerosis may explain the poor prognosis of areca nut chewers after ACS. However, the exact underlying biological mechanism that leads to repeated hospitalization and a slight increase in the risk of death needs further exploration.

To our knowledge, this is the first clinical study to examine the relationship between areca nut chewing and the shortterm prognosis of ACS patients. The prospective design and reasonably large sample with clinically diagnosed ACS make the findings of this study fairly robust. However, certain limitations need to be highlighted. The sample of this study was recruited from 2 public sector hospitals, and the majority of the patients were from low to lower-middle socioeconomic classes, which may limit the generalizability of this study. However, the areca nut chewing habit is also remarkably common in these SESs of the population [35], especially in comparison with the upper-middle and upper socioeconomic classes. Therefore, the sample recruited for this study may nonetheless be representative of middle-aged and elderly areca nut users in our population. Secondly, we relied on self-reporting of cigarette smoking and other health risk behaviors, which may have some potential to bias our results. For instance, the higher risk of re-hospitalization observed in this study may have been due to a differential distribution of health risk behaviors between areca nut chewers and non-chewers. Secondhand smoke is a particular concern in this regard, as higher exposure to secondhand smoke among areca nut chewers may have led to increased re-hospitalization in this group. This is fairly plausible because many health risk behaviors are usually clustered together, and it may be reasonable to assume that areca nut chewers would have a higher exposure to secondhand smoke than non-chewers. We do not have any evidence to support this possibility, but if it is true, the findings of this study may have been prone to confounding bias, which remains the major limitation of this study. Nevertheless, we attempted to control for the potential confounding effects of several covariates, and the overall findings of the study remained consistent after multivariate adjustments.

In conclusion, areca nut chewing significantly increased the risk of re-hospitalization among ACS patients; however, there is little evidence that it increased short-term mortality. Further evidence from large clinical studies is needed to validate our findings and to elucidate the biological mechanism underlying these observations.

\section{ACKNOWLEDGEMENTS}

We would like to acknowledge the Department of Cardiology, Civil Hospital Karachi and the National Institute of Cardiovascular Diseases for providing their support for data collection for this study.

\section{CONFLICT OF INTEREST}

The authors have no conflicts of interest associated with the material presented in this paper.

\section{ORCID}

Muhammad Tariq Karim https://orcid.org/0000-0001-8720$234 X$

Sumera Inam https://orcid.org/0000-0002-6110-5653

Tariq Ashraf https://orcid.org/0000-0002-6680-1017

Nadia Shah https://orcid.org/0000-0002-9166-2047

Syed Omair Adil https://orcid.org/0000-0002-2370-1390

Kashif Shafique http://orcid.org/0000-0001-7151-5122

\section{REFERENCES}

1. Pankaj C. Areca nut or betel nut control is mandatory if India wants to reduce the burden of cancer especially cancer of the oral cavity. Int J Head Neck Surg 2010;1(1):17-20.

2. Gupta PC, Ray CS. Epidemiology of betel quid usage. Ann Acad Med Singapore 2004;33(4 Suppl):31-36.

3. Niaz K, Maqbool F, Khan F, Bahadar H, Ismail Hassan F, Abdollahi M. Smokeless tobacco (paan and gutkha) consumption, prevalence, and contribution to oral cancer. Epidemiol Health 2017;39:e2017009.

4. Boucher BJ, Mannan N. Metabolic effects of the consumption of areca catechu. Addict Biol 2002;7(1):103-110.

5. Wollina U, Verma S, Parikh D, Parikh A. Oral and extraoral disease due to betel nut chewing. Hautarzt 2002;53(12):795-797 (German).

6. Sciubba JJ. Oral cancer. The importance of early diagnosis and treatment. Am J Clin Dermatol 2001;2(4):239-251.

7. Tsai JF, Jeng JE, Chuang LY, Ho MS, Ko YC, Lin ZY, et al. Habitual betel quid chewing and risk for hepatocellular carcinoma complicating cirrhosis. Medicine (Baltimore) 2004;83(3):176187.

8. Wu IC, Lu CY, Kuo FC, Tsai SM, Lee KW, Kuo WR, et al. Interac- 
tion between cigarette, alcohol and betel nut use on esophageal cancer risk in Taiwan. Eur J Clin Invest 2006;36(4):236241.

9. Hsiao TJ, Liao HW, Hsieh PS, Wong RH. Risk of betel quid chewing on the development of liver cirrhosis: a community-based case-control study. Ann Epidemiol 2007;17(6):479-485.

10. Yen AM, Chiu YH, Chen LS, Wu HM, Huang CC, Boucher BJ, et al. A population-based study of the association between betel-quid chewing and the metabolic syndrome in men. Am J Clin Nutr 2006;83(5):1153-1160.

11. Chung FM, Chang DM, Chen MP, Tsai JC, Yang YH, Shieh TY, et al. Areca nut chewing is associated with metabolic syndrome: role of tumor necrosis factor-alpha, leptin, and white blood cell count in betel nut chewing-related metabolic derangements. Diabetes Care 2006;29(7):1714.

12. Chang WC, Hsiao CF, Chang HY, Lan TY, Hsiung CA, Shih YT, et al. Betel nut chewing and other risk factors associated with obesity among Taiwanese male adults. Int J Obes (Lond) 2006; 30(2):359-363.

13. Tung TH, Chiu YH, Chen LS, Wu HM, Boucher BJ, Chen TH, et al. A population-based study of the association between areca nut chewing and type 2 diabetes mellitus in men (Keelung Community-based Integrated Screening programme No. 2). Diabetologia 2004;47(10):1776-1781.

14. Chou CY, Cheng SY, Liu JH, Cheng WC, Kang IM, Tseng YH, et al. Association between betel-nut chewing and chronic kidney disease in men. Public Health Nutr 2009;12(5):723-727.

15. Shafique K, Zafar M, Ahmed Z, Khan NA, Mughal MA, Imtiaz F. Areca nut chewing and metabolic syndrome: evidence of a harmful relationship. Nutr J 2013;12:67.

16. Zhang LN, Yang YM, Xu ZR, Gui QF, Hu QQ. Chewing substances with or without tobacco and risk of cardiovascular disease in Asia: a meta-analysis. J Zhejiang Univ Sci B 2010;11(9):681689.

17. Khan MS, Bawany Fl, Ahmed MU, Hussain M, Khan A, Lashari MN. Betel nut usage is a major risk factor for coronary artery disease. Glob J Health Sci 2013;6(2):189-195.

18. Lan TY, Chang WC, Tsai YJ, Chuang YL, Lin HS, Tai TY. Areca nut chewing and mortality in an elderly cohort study. Am J Epidemiol 2007;165(6):677-683.

19. Lin WY, Chiu TY, Lee LT, Lin CC, Huang CY, Huang KC. Betel nut chewing is associated with increased risk of cardiovascular disease and all-cause mortality in Taiwanese men. Am J Clin Nutr 2008;87(5):1204-1211.

20. McClintock TR, Parvez F, Wu F, Wang W, Islam T, Ahmed A, et al. Association between betel quid chewing and carotid intima-media thickness in rural Bangladesh. Int J Epidemiol 2014; 43(4):1174-1182.

21. Heck JE, Marcotte EL, Argos M, Parvez F, Ahmed A, Islam T, et al. Betel quid chewing in rural Bangladesh: prevalence, predictors and relationship to blood pressure. Int J Epidemiol 2012; 41(2):462-471.

22. Yamada T, Hara K, Kadowaki T. Chewing betel quid and the risk of metabolic disease, cardiovascular disease, and all-cause mortality: a meta-analysis. PLoS One 2013;8(8):e70679.

23. Grech ED, Ramsdale DR. Acute coronary syndrome: unstable angina and non-ST segment elevation myocardial infarction. BMJ 2003:326(7401):1259-1261.

24. Hasdai D, Behar S, Wallentin L, Danchin N, Gitt AK, Boersma E, et al. A prospective survey of the characteristics, treatments and outcomes of patients with acute coronary syndromes in Europe and the Mediterranean basin; the Euro Heart Survey of Acute Coronary Syndromes (Euro Heart Survey ACS). Eur Heart J 2002;23(15):1190-1201.

25. Tsai WC, Wu MT, Wang GJ, Lee KT, Lee CH, Lu YH, et al. Chewing areca nut increases the risk of coronary artery disease in Taiwanese men: a case-control study. BMC Public Health 2012; 12:162.

26. Kumar A, Cannon CP. Acute coronary syndromes: diagnosis and management, part I. Mayo Clin Proc 2009;84(10):917938.

27. WHO Expert Consultation. Appropriate body-mass index for Asian populations and its implications for policy and intervention strategies. Lancet 2004;363(9403):157-163.

28. Tseng $\mathrm{CH}$. Betel nut chewing and subclinical ischemic heart disease in diabetic patients. Cardiol Res Pract 2010;2011: 451489 .

29. Al-Sharabi AK, Shuga-Aldin H, Ghandour I, Al-Hebshi NN. Qat chewing as an independent risk factor for periodontitis: a cross-sectional study. Int J Dent 2013;2013:317640.

30. IARC Working Group on the Evaluation of Carcinogenic Risks to Humans. Betel-quid and areca-nut chewing and some areca-nut derived nitrosamines. IARC Monogr Eval Carcinog Risks Hum 2004;85:1-334.

31. World Health Organization. Global status report on noncommunicable diseases 2010: description of the global burden of NCDs, their risk factors and determinants; 2011 [cited 2017 Apr 1]. Available from: http://www.who.int/nmh/publications/ncd_report2010/en/.

32. Tsai WC, Chen CY, Kuo HF, Wu MT, Tang WH, Chu CS, et al. Are- 
ca nut chewing and risk of atrial fibrillation in Taiwanese men: a nationwide ecological study. Int J Med Sci 2013;10(7):804811.

33. Lin SH, Liao YS, Huang SH, Liao WH. Relationship between betel quid chewing and risks of cardiovascular disease in older adults: a cross-sectional study in Taiwan. Drug Alcohol Depend 2014;141:132-137.
34. Shafique K, Mirza SS, Vart P, Memon AR, Arain MI, Tareen MF, et al. Areca nut chewing and systemic inflammation: evidence of a common pathway for systemic diseases. J Inflamm (Lond) 2012;9(1):22.

35. Hashibe M, Jacob BJ, Thomas G, Ramadas K, Mathew B, Sankaranarayanan $\mathrm{R}$, et al. Socioeconomic status, lifestyle factors and oral premalignant lesions. Oral Oncol 2003;39(7):664-671. 